\title{
Reliable in situ rock stress measurement from the excavation surface
}

\author{
T Siren Stress Measurement Company, Finland \\ M Hakala Stress Measurement Company, Finland \\ MA Perras Stress Measurement Company, Canada
}

\begin{abstract}
Measuring rock stress has always been a challenging task. Although borehole overcoring stress methods produce a 3D stress state if multiple measurements at different orientations are conducted, the variation in the result is commonly high and only representative of a small area that can be affected by local geology. Furthermore, these methods suffer from low success rates because of glue-related problems or core disking in highly stressed rocks. To overcome these problems, a new method was developed to measure the induced stresses in the vicinity of an excavated surface and further to use these results to interpret the in situ state of stress at the excavation-scale. The new linear variable differential transformer (LVDT) cell method described in this paper produces a 3D stress state while being less expensive than traditional methods, fast, and produces more repeatable and reliable results. Key advances are glueless mounting, utilisation of a compact drill rig, and side coring technique for high-stress conditions to overcome core disking. The reliability of the solution has been proven by comparing against known rock stress conditions at the Äspö Hard Rock Laboratory in Sweden. Since 2009, in situ stress measurements have been carried out at over 10 sites in Scandinavia in underground laboratories, hydropower excavations and mines from $15 \mathrm{~m}$ up to 1.4 $\mathrm{km}$ below surface. Also, the method is in production use in several mines, proving it to be a reliable source of data for the changing stress field around the mine during production.
\end{abstract}

Keywords: in situ, stress, measurement, rock, overcoring, sidecoring, LVDT cell

\section{Introduction}

Understanding the in situ stress field around an excavation is a very important input into the design process and necessary for continued successful excavation development. In complex mining environments, the local stress field changes during development and so requires re-visiting the design input values to address changes. Understanding the stresses at the excavation surface and how they may change with new developments also allows for optimisation of rock support, so that the right support (not over or under-designed) can be installed. Finally, it is an important parameter for simulating stress redistribution in order to control risk and guarantee production. There are several well-known methods typically in use, which have well-known limitations.

The limitations related to hydraulic fracturing and overcoring measurements are in part due to the small-diameter boreholes. Both methods can be affected by borehole-scale heterogeneity. Furthermore, overcoring can suffer from glue-related problems (especially in cold environments), such as thermal reactivation and de-bonding (Lahaie et al. 2010; Berg \& Sjöberg 2009) and hydraulic fracturing can give unreliable stress magnitudes if both horizontal stress components are greater than the vertical stress (Evans \& Engelder 1989; Doe et al. 2006). These issues can cause large variations and the scattered data is often hard to interpret from typically a small number of measurements conducted. Thus, one solution is a large number of measurements to reach a reliable interpretation, however, this is usually not realistic for most projects due to high costs. 
In 2004, the excavations of the underground rock characterisation facility for spent nuclear fuel started in Olkiluoto, Western Finland. This was the beginning for a new start in rock mechanics research and developments in Finland. At this facility, the rock mass was further characterised from the initial campaign at surface when the excavations progressed towards the current depth of $-457 \mathrm{~m}$ (Posiva 2012). One of the hardest parameters to characterise was the in situ stress and the following (typical) problems where faced during characterisation: glue de-bonding problems of the measurement cell during overcoring, scattered overcoring and hydraulic fracturing data and local geology affecting the stress measurement results (Hakala et al. 2012). The largest impact was the local heterogeneity in geology, which tended to change the stress measurement results, similar to the observations of Martin et al. (1990) who outlined that data scatter is larger with a smaller measurement volume.

For the challenging geological conditions of Olkiluoto a new stress measurement technique was developed to measure the induced stresses in the vicinity of an excavated surface and further to use these results to interpret the in situ state of stress at the excavation-scale. The new linear variable differential transformer (LVDT) cell method was first introduced by Hakala et al. (2012) demonstrating the production of a 3D stress state while being inexpensive, fast and reliable. Key advances are large measurement volume, glueless mounting of the measurement cell, utilisation of a compact drill rig and side coring technique for high-stress conditions.

\section{Description of the method}

The new LVDT cell measurement technique comprises of a new fully mechanical large-scale cell and a new methodology to measure secondary stresses around an excavation perimeter and to use an inverse calculation to convert it into the in situ far field stress state. The process is comprised of five phases (illustrated in Figure 1) and outlined as follows:

- Shallow overcoring measurement from the excavation surface. The overcoring is conducted using large borehole sizes further increasing the accuracy.

- 3D photogrammetry of the measurement location.

- Testing of deformability properties (Young's modulus and Poisson's ratio) of the rock in the laboratory.

- 3D modelling of the excavation perimeter to take into account the excavation and hole geometries (different hole sizes indicated in Figure 1, step 4, by different colours).

- Best fit solution of the measurements to the 3D modelling results with full stress tensor and error estimates.

The measurements are conducted with the LVDT cell which measures the diametric deformation of the pilot hole wall, when it is either totally (overcoring) or partially (sidecoring) released from the secondary stress state. This secondary stress state is defined by the in situ stresses and redistributed by the excavation and the pilot hole geometry. Normally, the measurements are done in at least half a metre of depth from the excavation surface to avoid the construction-induced damage zone (CDZ) caused by drill and blast excavation methods, described in detail by Siren et al. (2015) and Perras and Diederichs (2016). In some cases, shorter installation depths are used because of natural fracturing but in these cases excavation damaged sections are not less likely. Typically, the installation depth varies between 0.5 and $1.3 \mathrm{~m}$. The measurement is repeated in different directions, typically in four to five holes in one excavation profile, used in one in situ stress interpretation.

The in situ stress at the measurement location is interpreted based on all accepted measurement values using a best fit inversion solution. This solution method requires the 3D geometry of the excavation and measurement holes and the elastic properties of rock. The geometry is obtained by 3D photogrammetry and simplified into a 3D boundary element mesh. For continuous homogeneous isotropic linear elastic conditions, the boundary element (BEM) code Examine ${ }^{3 D}$ (Rocscience 2017) is used to calculate LVDT 
head displacements caused by six unit in situ stress tensor components. Finite element modelling (FEM) can also be done for more complex geological situations. The elastic constants needed for these models are interpreted from uniaxial compression tests results of pilot hole cores. The applied best fit inverse solution multiplies and superimposes the calculated LVDT head displacements caused by six unit stress tensors to fit with measured convergences. The best fit solution gives the in situ stress affecting the measurement location.

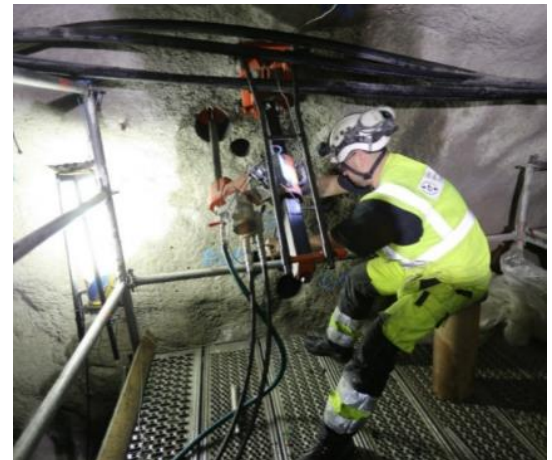

$\underline{\text { Step } 1}$

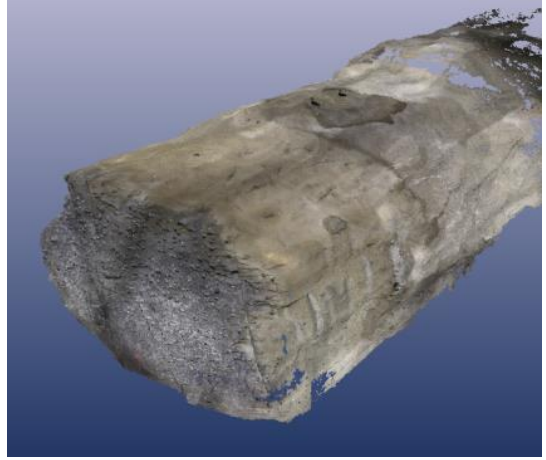

Step 2

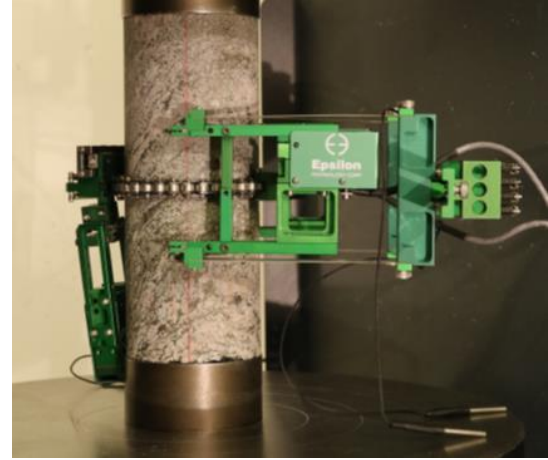

$\underline{\text { Step } 3}$

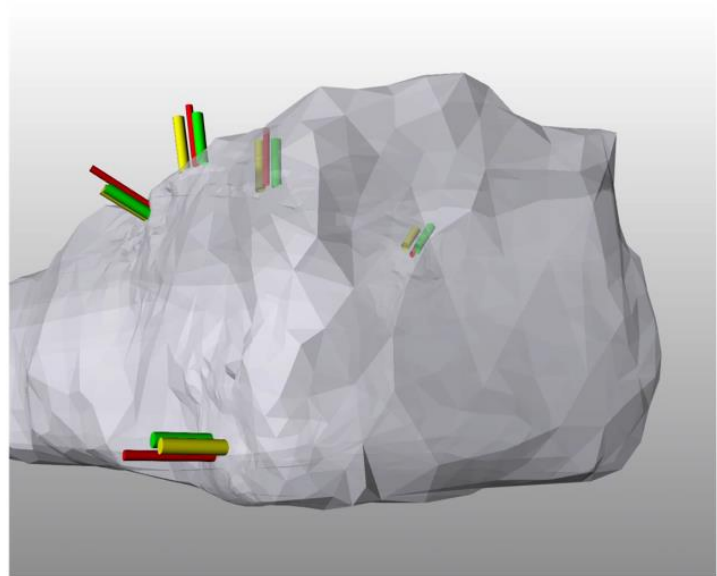

Step 4

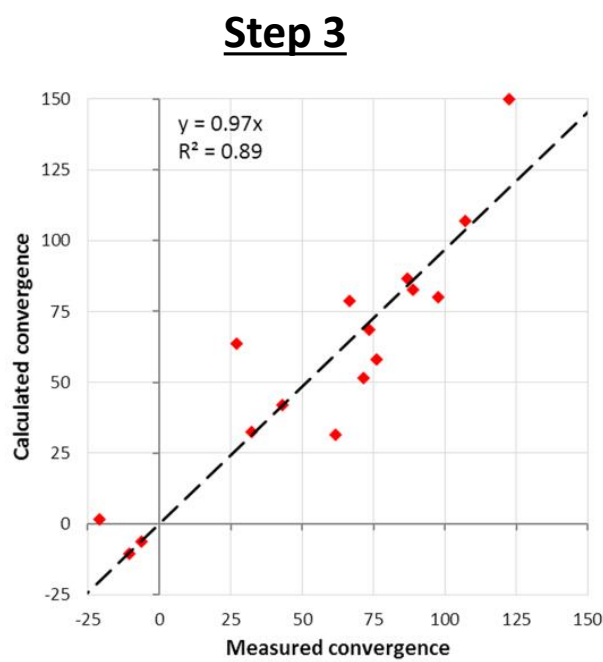

$\underline{\text { Step } 5}$

Figure 1 Illustration of the LVDT cell stress measurement process

For quality assurance, the field work is controlled by a log sheet including all important work phases. As part of the field work, the LVDT cell is calibrated before and after each measurement to check the accuracy and linearity of the gauges. Before the inverse solution, the consistency of each LVDT measurement and laboratory measurement of the deformation properties are checked. Finally, the inverse solution gives statistics to judge the reliability.

\section{$2.1 \quad$ The LVDT cell}

The LVDT cell measures the radial convergence along four diameters of the pilot hole using eight LVDTs. The diametric deformations have been found to be more accurate than radial deformations. The LVDT sensors provide high accuracy of $0.1 \mu \mathrm{m}$ over the $127 \mathrm{~mm}$ diameter of the pilot (better than $1 \mathrm{ppm}$ ). The cell is waterproof and is equipped with temperature sensors to measure the rock temperature. Calibration of the cell is done before and after each measurement using a special calibration cylinder made of aluminium. The cell is attached to the pilot hole tightly using two expansive o-rings.

After installation beyond the excavation damage zone (EDZ), the stability of the mounting and LVDT-sensor contacts with the rock wall are checked manually and if permanent changes over five micrometres take place the cell contacts are re-checked. In case of repetitive permanent changes, the cell is tightened or 
remounted until stable conditions are achieved. After this manual check, the cell is monitored for at least 15 minutes; drift less than five micrometres per $15 \mathrm{~min}$ is required in order to proceed to the measurement phase. During the overcoring, the deformation of the pilot hole (cell installation hole) is monitored with the LVDT sensors, resulting in four convergence measurements (Figure 2). The use of four convergences has been found more reliable than the use of eight radial measurements, because in this case the cell mounting does not have to be $100 \%$ rigid.

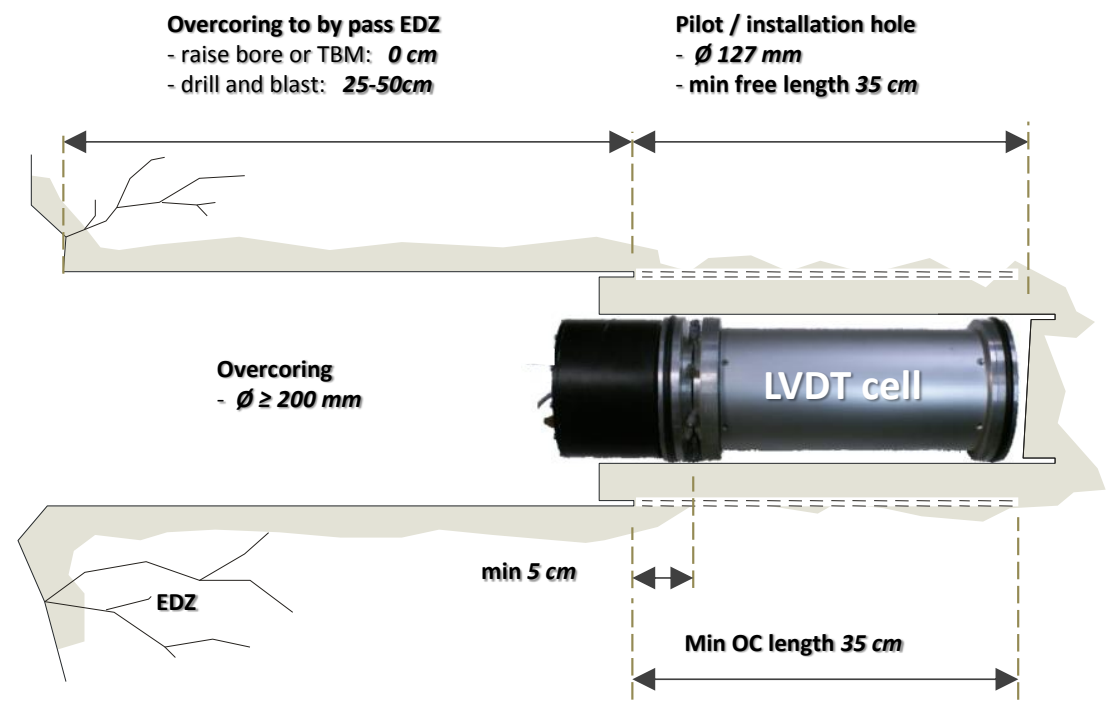

Figure 2 LVDT cell with measurement from the excavation surface usually done in drill and blast excavations beyond the construction and excavation damage zones (CDZ and EDZ)

After overcoring, the thermal effects from the coring-induced heat and flushing water must stabilise before reading is stopped and the cell is recovered. Normally, two hours is sufficient to settle temperatures to be less than $\pm 2^{\circ} \mathrm{C}$ from initial value. The stabilising time can be reduced if no temperature increases are found. Usually measurements have good stability of a few $\mu$ m over 12 hours.

\subsection{Numerical inversion calculation method}

The in situ stress state is determined from the overcoring measurements of the secondary stress state by conducting an inversion fit of the convergences to the most probable in situ stress state.

The inversion process requires a 3D model with the excavation surface of the model based on a 3D photogrammetric model that was created from photos taken from the measurement location. The 3D finite element model (FEM) or boundary element (BEM) model is run in six unit tensor combinations - one of the in situ stress tensor components is set equal to $1 \mathrm{MPa}$ and the other components are set to zero. Results give displacements at each LVDT sensor head. In the case of linear elasticity, the LVDT sensor head displacements, caused by any in situ stress state, i.e. $\left(k \times \sigma_{E E}, 1 \times \sigma_{N N}, m \times \sigma_{U U}, n \times \sigma_{E N}, o \times \sigma_{N U}, p \times \sigma_{U E}\right)$, can be constructed by superimposing the multiplied displacement components caused by each stress tensor component (Equation 1):

$$
\begin{aligned}
u_{i}\left(k \sigma_{E E}, l \sigma_{N N}, m \sigma_{U U}, n \sigma_{E N}, o \sigma_{N U}, p \sigma_{U E}\right)= & k \times u_{i}\left(\sigma_{E E}=1\right)+l \times u_{i}\left(\sigma_{N N}=1\right)+ \\
& m \times u_{i}\left(\sigma_{U U}=1\right)+n \times u_{i}\left(\sigma_{E N}=1\right)+ \\
& o \times u_{i}\left(\sigma_{N U}=1\right)+p \times u_{i}\left(\sigma_{U E}=1\right)
\end{aligned}
$$

where:

$$
\begin{aligned}
& u_{i}=\text { is the orthogonal displacement component, } i=\text { east, north, up. } \\
& \sigma_{i i}=\text { is the orthogonal stress tensor component, } i=\text { east, north, up. } \\
& k \ldots p=\text { are multipliers for stress tensor components and displacement components caused by each } \\
& \quad \text { stress tensor component. }
\end{aligned}
$$


The solution for multipliers $(k, l, m, n, 0, p)$ is found iteratively. The accepted solution is the one that provides the best fit between the calculated convergence and the measured values. The solution represents the in situ stress state most likely to have caused the convergences during overcoring. By comparing the measured and calculated convergences, the mean error of the result can be determined (see Figure 3 for an illustrative example). Often the case is that convergences in one hole differ from the solution, however, the trend is clear. This can usually be attributed to geological features disturbing the stress field locally.

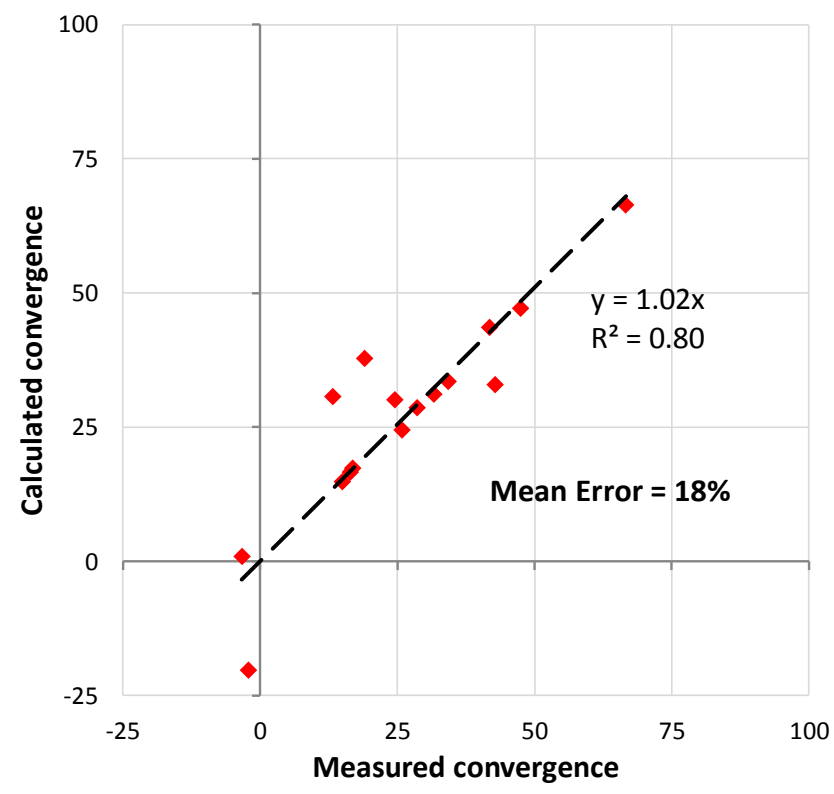

Figure 3 Estimation of the quality of the measurement based on the 3D inversion (Hakala 2016)

\subsection{Taking geological features into account}

Easily identifiable geological features, such as different rock types, foliation, distinct fractures or lithological boundaries, can be taken into account within the normal limits of numerical 3D modelling and linear elasticity. In Figure 4, the effect of different computational models (BEM and FEM), transverse isotropy, effect of a brittle fault zone below the excavation, existence of an excavation damage zone and heterogeneous rock properties to the inversion calculation results are shown. The different solutions have an especially significant effect on the intermediate and major principal stresses. The most appropriate solution can be determined by investigating the mean error related to each result. 

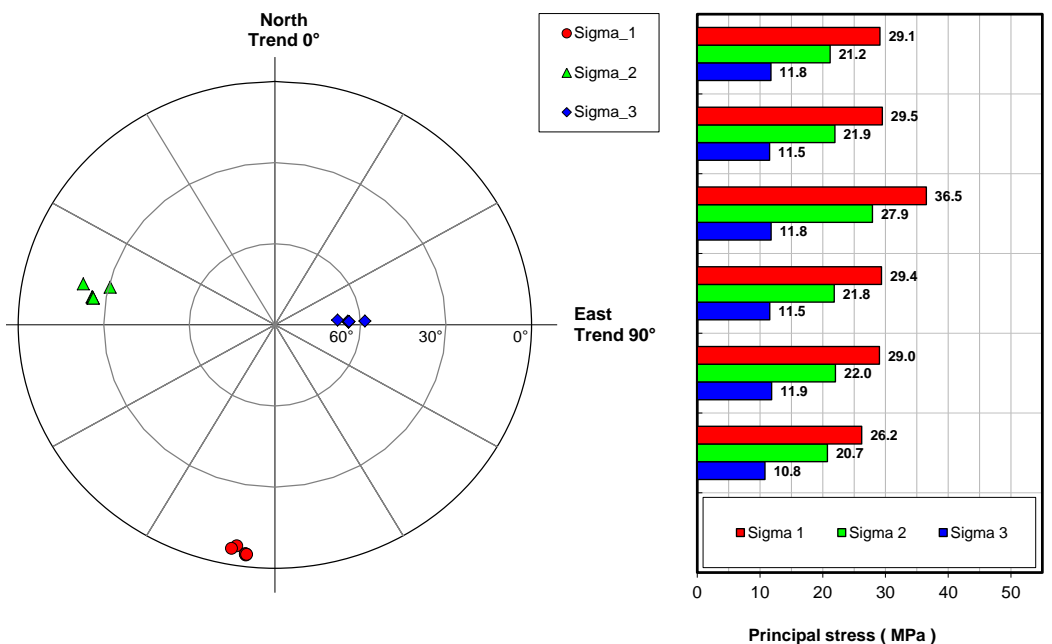

BEM

FEM

Transverse isotropy $\mathrm{E} / \mathrm{E}^{\prime}=1.4$

Effect of BFZ below floor

$E D Z, E_{E D Z} / E=0.8, r=0.25 \mathrm{~m}$

Heterogeneity, $\mathrm{E}_{\mathrm{i}}=31-68 \mathrm{GPa}$

Figure 4 Effect of different computational models (BEM and FEM), transverse isotropy, effect of brittle fault zone (BFZ) below the excavation, excavation damage zone (EDZ) and heterogeneous rock properties to the inversion calculation results (Hakala 2016)

\subsection{Measurement at high stresses - avoiding core disking problems}

Core disking is a problem when overcoring rock stress measurements are conducted deep underground. The problem is related to the disking of the hollow cylinder that is under measurement. When cylinder disking occurs, as shown in Figure 5, the stresses are relieved instantly and often before the measurement has been fully carried out. This makes overcoring measurements in deep environments very difficult, if not impossible with traditional methods.

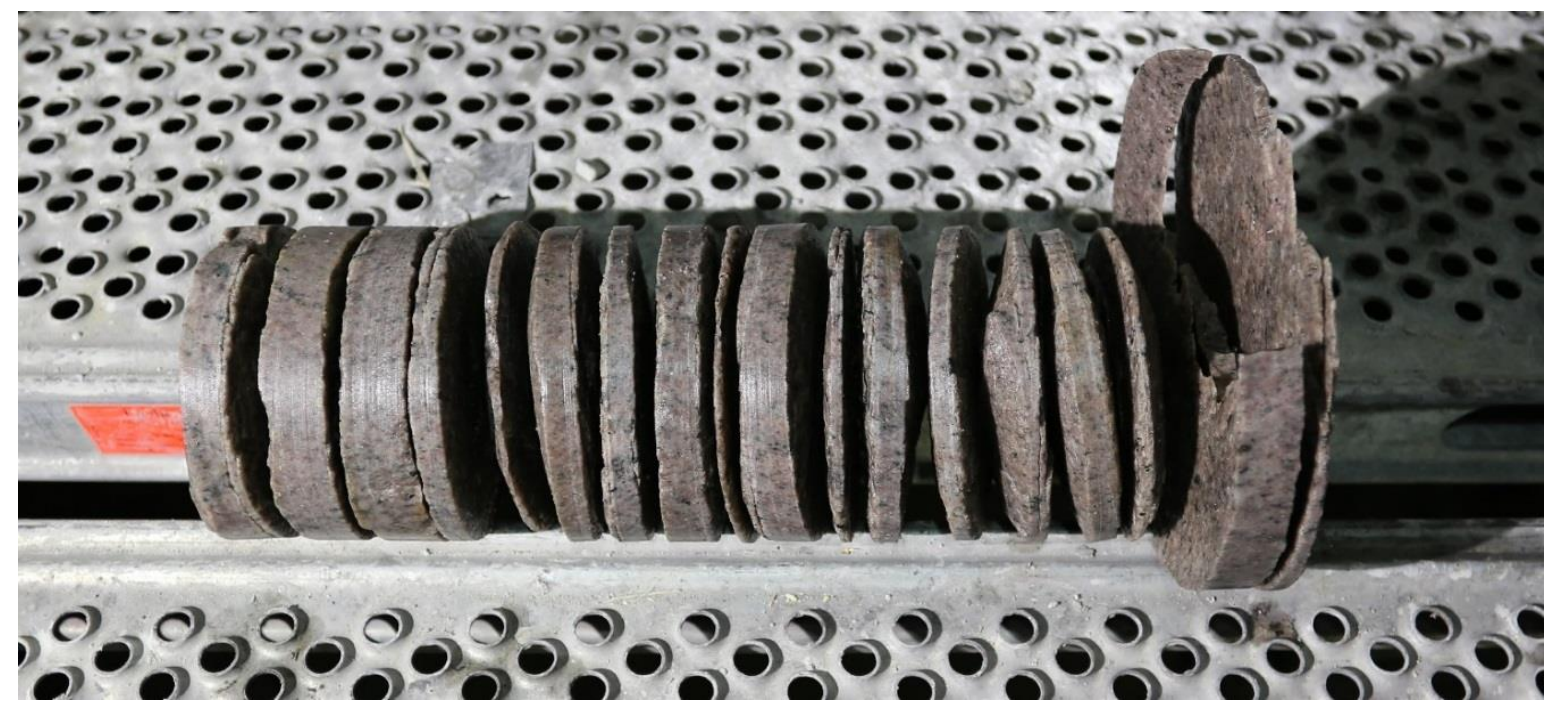

Figure 5 Typical core disking problem encountered in high-stress conditions

To overcome this problem, in the LVDT cell stress measurement method, the measurement can be carried out using the sidecoring technique where the stresses are released from the sides of the measurement hole using two large-diameter holes drilled $90^{\circ}$ apart from each other. In Figure 6 , an example from a high-stress environment is presented with successful sidecoring measurement despite minor spalling occurring at the stress release holes. It should be noted that, as seen in Figure 6 , the spalling of the pilot hole was initiated after the measurement was completed. 


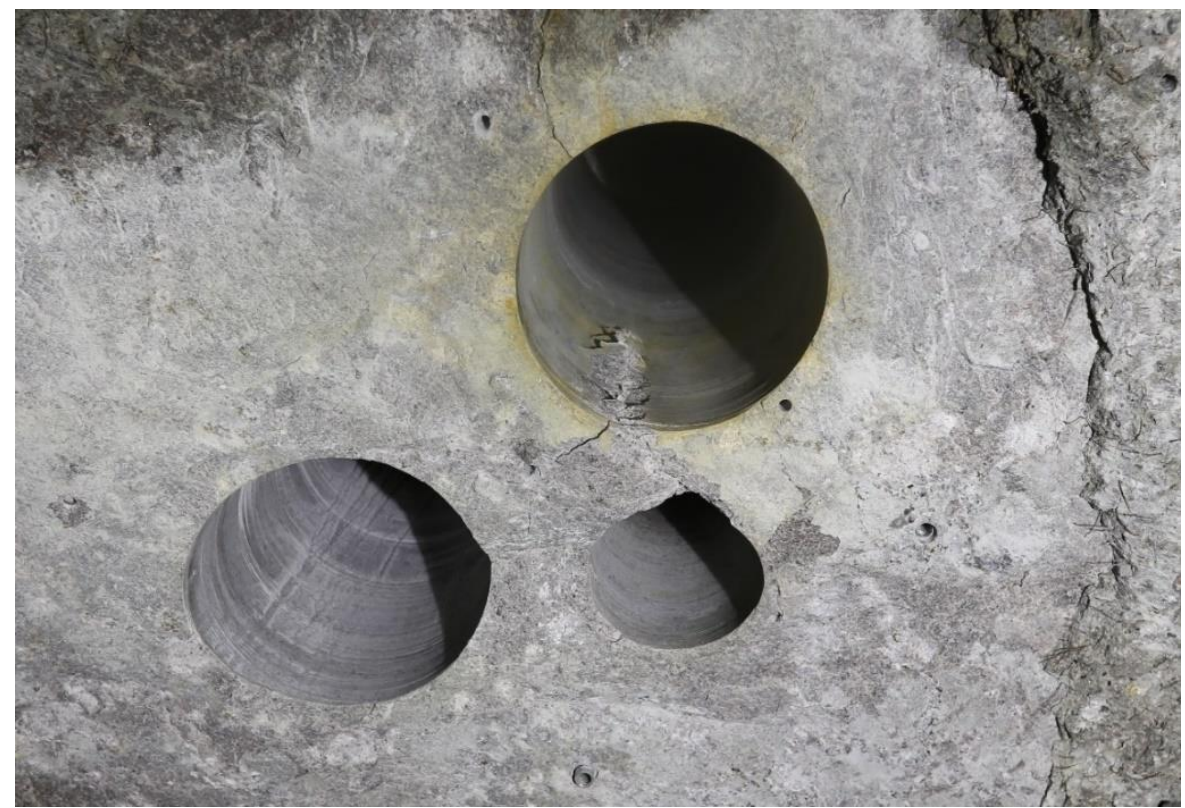

Figure 6 Side coring technique, large-diameter holes beside the smaller measurement hole, to conduct stress measurements in deep mines to avoid core disking and other high-stress problems in the measurement hole. In the small diameter hole, a notch is formed at the top indicating high-stress problems in this photograph

\subsection{Verification of the method}

The evaluation of the LVDT cell to provide a reliable measurement of the in situ state of stress was carried out in a drill and blast and a tunnel boring machine (TBM) excavation at the Äspö Hard Rock Laboratory in Sweden, from 2010 to 2012. The state of stress established using the LVDT cell was in agreement with the state of stress established previously using traditional overcoring and hydraulic fracturing methods. The results of Christiansson and Jansson (2003) reporting stress measurements in two orthogonal boreholes at $-450 \mathrm{~m}$ in the Äspö Hard Rock Laboratory using the Atomic Energy of Canada Limited deep doorstopper (DDGS), the Borre triaxial overcoring cell and hydraulic fracturing, and the principal stress directions acquired from the LVDT cell stress measurements (Hakala et al. 2014) are compared in Table 1.

Table 1 Comparison of test results to earlier best estimate of state of stress at the $450 \mathrm{~m}$ level

\begin{tabular}{lllll}
\hline Study & $\sigma_{\mathrm{H}}(\mathrm{MPa})$ & $\sigma_{\mathrm{H}}$ trend $(\mathrm{RT90})$ & $\sigma_{\mathrm{h}}(\mathrm{MPa})$ & $\sigma_{\mathrm{v}}(\mathrm{MPa})$ \\
\hline Christiansson and Jansson (2003) & $24 \pm 5$ & $136^{\circ}$ & $10-13$ & $15-20$ \\
Hakala et al. (2014) & $24-25$ & $136-152^{\circ}$ & $12-18$ & $10-18$
\end{tabular}

Further, it was found that the EDZ does not affect the resulting stress state if measurements are done at least at $0.5 \mathrm{~m}$ from the excavation surface, however, if it is done near the surface the magnitude will be inaccurate but the orientation will be consistent. Further results are reported in detail in Hakala et al. (2014).

\section{Measurements in Northern Europe}

After the development of the method, measurements have been conducted in hard rock regions in Northern Europe at different depths. In Northern Europe, the general trend of the major principal stress state is aligned northwest-southeast, dominated largely by tectonic plate boundary forces. Since the development and start of commercial use of the LVDT cell, stress measurements have been conducted at numerous locations (e.g. in Malmberget, Pyhäsalmi, Kemi and Kylylahti mines; hydropower excavations; the Finnish spent nuclear fuel project and in Stockholm's Henriksdal wastewater treatment plant). The 
measurement range is from a depth of $15 \mathrm{~m}$ up to $1.4 \mathrm{~km}$ below the ground level. The LVDT stress measurement results produced a consistent trend in the northwest-southeast direction. As can be expected, the near-surface measurements in Helsinki and Stockholm have more variation compared to measurements at depth (Figure 7).

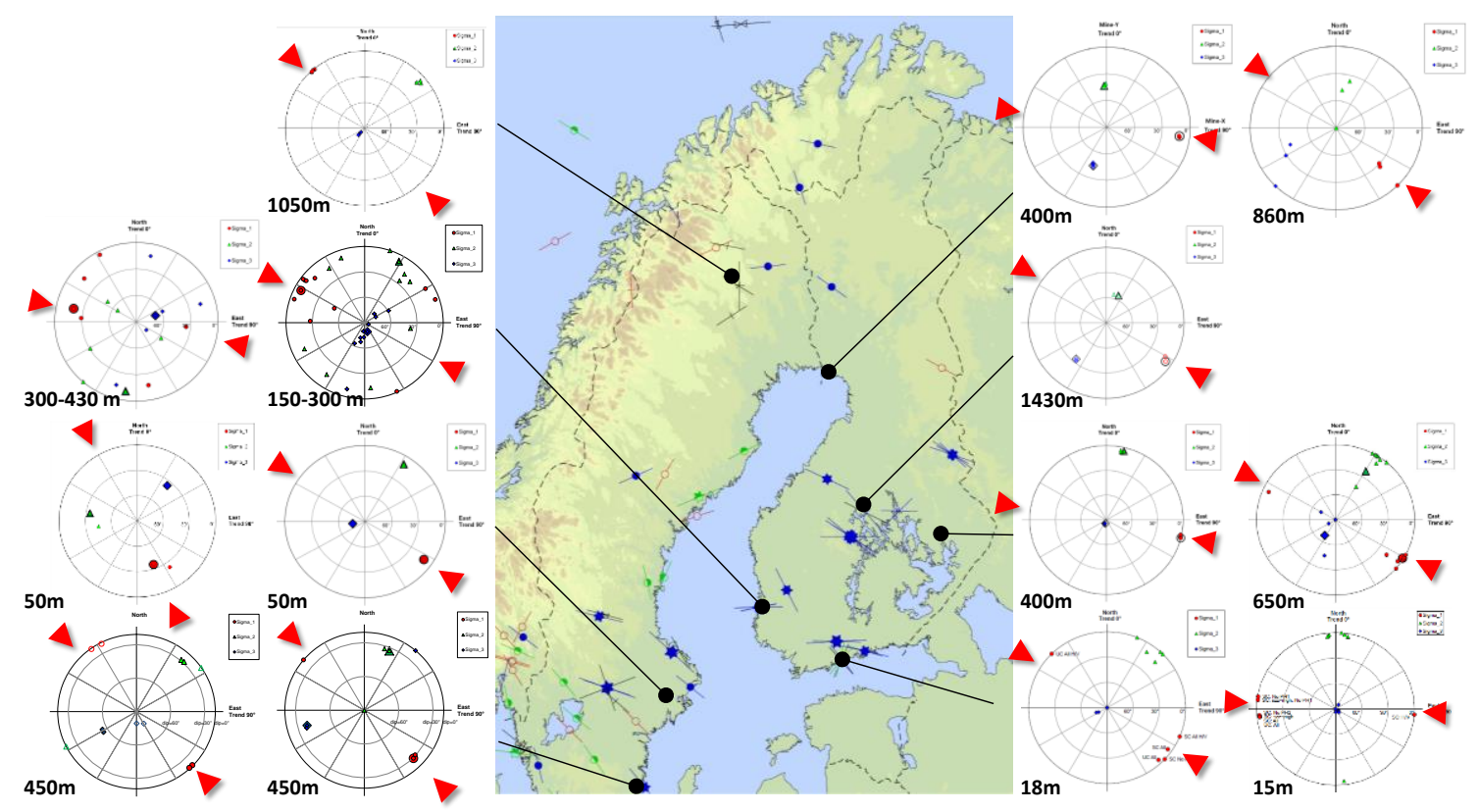

Figure 7 Stress measurement results from Scandinavia using LVDT cell measurement method (Hakala 2016). Reference data from World Stress Map (Heidbach et al. 2016)

\section{Conclusion}

The new LVDT stress measurement method was developed to meet the need for fast and reliable measurement of rock stresses. Since the development and start of commercial LVDT stress measurements, the results at deep underground laboratories, excavation projects and mines have produced consistent magnitudes and trends, to the northwest-southeast direction, in Scandinavia, which agrees well with other stress measurement methods and the World Stress Map trends. Measurements up to $1.4 \mathrm{~km}$ below ground level have been conducted with great success and the sidecoring technique has proven to be a reliable method when high stress to strength ratios are observed.

The reliability of the solution has been proven by comparing against known rock stress conditions and measurements using other methods at the Äspö Hard Rock Laboratory in Sweden, with measurements in Olkiluoto, Finland (Hakala et al. 2017) and Malmberget mine, Sweden (Wettainen \& Jonsson 2017). The extensive testing of the LVDT cell shows it to be robust and suitable for use in an underground environment and it can withstand a range of operating conditions while still providing acceptable results. Also, the method is in production use in several mines, proving it to be a reliable source of data for the changing stress field around the mine during production.

The in situ stress at the measurement location can be solved by numerical inversion using the results of at least three overcoring or sidecoring measurements around the three-dimensional excavation section. The large dimensions of the measurement tool and the ability to utilise multiple measurements at various locations in an excavation section provides flexibility in selecting an appropriate rock mass volume to minimise influence from excavation damage and other adverse geological features. The effect of geological features, excavation damage zone and rock heterogeneity was tested and can be taken into account in the inverse solution (Figure 7). 
In summary, LVDT cell measurement technology is a reliable and accurate method based on the following reasons:

- The large dimension $(120 \mathrm{~mm})$ of the measurement cell allows to avoid problems with small-scale rock heterogeneity and gives larger displacements. With the larger tool dimensions, it has been possible to include accurate LVDT sensors that can measure movements up to $0.1 \mu \mathrm{m}$.

- The cell structure allows measurement of radial convergence on four diameters using eight LVDTs in different directions, and thus the tool is robust for any movements during overcoring.

- The measurement tool is fully mechanical, thus any problems encountered with glueing of strain gauges can be avoided and coupling of the tool with the borehole wall is more reliable.

- The overcoring or sidecoring is conducted at the excavation surface making it fast to conduct. The typical measurement depth is possible between 0.5-1.0 m, typically beyond the excavation damage zone. As the method relies on the induced stresses, which are concentrated and increased from the far field at the excavation perimeter increasing the measured displacements. Larger readings increase reliability of the measurement.

- The method integrates multiple overcoring or sidecoring measurements (typically four to five per excavation section) in the in situ stress interpretation. The in situ stress at the measurement location is solved by numerical inversion with no presumptions about in situ stress direction required. The ability to utilise multiple measurements at various locations in an excavation section provides flexibility in selecting an appropriate rock mass volume.

- The LVDT cell measurement technology and method has been verified and evaluated to provide the in situ state of stress in drill and blast and TBM excavations at various sites and good agreement with other methods has been achieved.

\section{Acknowledgement}

Co-authors from previous publications, and Posiva, Finland and SKB, Sweden are gratefully acknowledged for their assistance with verification work of the measurement method.

\section{References}

Berg, S \& Sjöberg, J 2009, Overcoring Rock Stress Measurements in Drillholes ONK-PP169 and ONK-PP170 Olkiluoto, Posiva Working Report 2009-20, Posiva Oy, Eurajoki.

Christiansson, R \& Jansson, T 2003, 'A test of different stress measurement methods in two orthogonal bore holes in the Äspö Hard Rock Laboratory (HRL), Sweden', International Journal of Rock Mechanics and Mining Sciences, vol. 40, no. 7-8, pp. 1161-1172.

Doe, TW, Zieger, M, Enachescu, C \& Böhner, J 2006, 'In situ stress measurements in exploratory boreholes', Felsbau, vol. 24, no. 4, pp. 39-47.

Evans, K \& Engelder, T 1989, 'Some problems in estimating horizontal stress magnitude in thrust regimes', International Journal Rock Mechanics Mining Science \& Geomechanics Abstracts, vol. 26, no. 6, pp. 647-660.

Hakala, M 2016, LVDT Cell Method - and Development of In situ Stress Measurement Techniques in Finland, session keynote at the 7th International Symposium on In Situ Rock Stress held from May 10-12 2016, Tampere.

Hakala, M, Hakala, V, Heine, J, Kemppainen, K, Savunen, J, Sireni, S, Siren, T, Ström, J \& Valli, J 2017, In Situ Stress Measurements in ONKALO with LVDT - Cell, Posiva Report 20-2016, Posiva Oy, Eurajoki.

Hakala, M, Kemppainen, K, Siren, T, Heine, J, Christiansson, R, Martin, CD \& Koskinen, T 2012, 'Experience with a new LVDT cell to measure in situ stress from an existing excavation', Proceedings of the 2012 ISRM International Symposium: EUROCK 2012, International Society for Rock Mechanics, Lisbon.

Hakala, M, Siren, T, Kemppainen, K, Christiansson, R \& Martin, CD 2014, In situ Stress Measurement with LVDT Cell - Method Description and Verification, Posiva Report 2012-43, Posiva Oy, Eurajoki.

Heidbach, O, Rajabi, M, Reiter, K \& Ziegler, M 2016, World Stress Map 2016, GFZ Data Services, https://doi.org/10.5880/WSM.2016.002

Lahaie, F, Gunzburger, Y, Ben Ouanas, A, Barnichon, JD \& Piguet, JP 2010, 'Impact of epoxy glue curing time on the quality of overcoring stress measurements in low-temperature environments', Proceedings of the 5th International Symposium on In situ Rock Stress, International Society for Rock Mechanics, Lisbon. 
Martin, CD, Read, RS, \& Chandler, NA 1990, 'Does scale influence in situ stress measurements? - Some findings at the Underground Research Laboratory', Proceedings of the First International Workshop on Scale Effects in Rock Masses, A.A. Balkema, Rotterdam, pp. 307-316.

Perras, M \& Diederichs, M 2016, 'Predicting excavation damage zone depths in brittle rock', Journal of Rock Mechanics and Geotechnical Engineering, vol. 8, no. 1, pp. 60-74.

Posiva 2012, Olkiluoto Site Description 2011, Posiva Report 2011-02, Posiva Oy, Eurajoki.

Rocscience 2017, Examine ${ }^{3 D}$, Rocscience Inc., Toronto, viewed 11 July 2017, https://www.rocscience.com/rocscience/products/ examine3d

Siren, T, Rinne, M \& Kantia, P 2015, 'Considerations and observations of stress-induced and construction-induced excavation damage zone in crystalline rock', International Journal of Rock Mechanics and Mining Sciences, vol. 73, pp. 165-174.

Wettainen, T \& Jonsson, K 2017, 'Stress measurements in LKAB Malmberget mine', Proceedings of Bergmekanikdagen 2017, Swedish Rock Mechanics Group, in Swedish. 